\title{
Pedigree analysis of Czech Holstein calves with schistosoma reflexum
}

\author{
Jindrich Citek
}

\begin{abstract}
Background: Schistosoma reflexum (SR) is congenital syndrome briefly characterized by visceral eventration, severe dorsoflexion and ankylosis of the spine and arthrogryposis. A genetic etiology has been proposed, but conclusive evidence has not yet been provided.

Methods: Pedigree analysis was carried out in 29 cases of SR in Czech Holsteins and Holstein crosses. Genetic relationship was evaluated and inbreeding coefficients calculated. Pedigrees of 15 Czech Holsteins fathering non-SR affected calves were used for comparison.

Results: Twenty-one cases occurred in one pedigree founded by three sires while three SR calves occurred in another pedigree with a common grandfather. The sex ratio between affected males and females was 11:6. Affected calves shared common ancestors different from those shared by the unaffected calves. The inbreeding coefficient in the SR affected calves was not increased compared to unaffected calves.

Conclusions: The findings are consistent with SR being inherited autosomal recessively. Further studies are however needed to confirm this and therefore a breeding trial is recommended where a suspected heterozygous sire is mated to closely related females.
\end{abstract}

Keywords: Cattle, Schistosoma reflexum, Inheritance, Congenital, Malformation

\section{Background}

Schistosoma reflexum (SR) is congenital syndrome briefly characterized by severe abdominal fissure with total eventration of viscera, marked dorsoflexion, and ankylosis of the spine and limbs. It occurs in all food animals, but is most common in cattle. SR usually requires assisted delivery, in most cases Caesarean section or foetotomy $[1,2]$. Although SR is rare, the high risk of dystocia in such cases is a welfare problem and the required veterinary assistance has a negative economic impact on farm economy.

Most studies of SR have dealt with the morphology of the syndrome [2-4], although some authors have also proposed a genetic background [5]. However, conclusive evidence has not yet been provided.

\footnotetext{
Correspondence: citek@zf.jcu.cz
}

Department of Genetics and Animal Breeding, Faculty of Agriculture, South Bohemia University, Studentska 13, Ceske Budejovice CZ37005, Czech Republic

\section{Ciomed Central}

This study was performed to further evaluate a possible genetic aetiology through pedigree analysis of multiple SR cases in Czech Holstein cattle.

\section{Methods}

Twenty-nine cases of SR diagnosed and reported by veterinary surgeons to the Czech surveillance program for bovine genetic disorders were included. The study was limited to Holstein and Holstein-crossbred calves fathered by sires born between January 1986 and December 2001. The sires were born in the Czech Republic or included in the herd book due to semen import. Parentage control was not performed to confirm registered descent. The cases occurred on farms spread across the Czech Republic. Six cases were females, 11 were males while the sex was not recorded in 12 cases.

The pedigree of each case was examined for common maternal and paternal ancestors (inbreeding loops) and for ancestors shared by other cases. When different cases shared a common ancestor combined pedigrees were constructed. 
Wright's inbreeding coefficient (Fx) was calculated when a common maternal and paternal ancestor was found by the equation:

$$
\mathrm{Fx}=\Sigma 0.5 \mathrm{n}_{1}+\mathrm{n}_{2}+1
$$

Where $n_{1}$ and $n_{2}$ are the number of generations between the SR affected calf and the common ancestor in the paternal and maternal part of the pedigree, respectively.

Pedigrees of 15 SR unaffected Holstein calves being progeny of sires that had not registered SR affected progeny and born in the same period as sires having registered SR affected progeny were sampled from the Plemdat database [6] at random. These sires were used as controls, i.e. their pedigrees were evaluated for the presence of sires genetically associated with SR affected calves and their inbreeding coefficient was calculated.

\section{Results}

Although the diagnosis of SR was based on field observations by a number of veterinary surgeons, the diagnoses are considered reliable as the morphology of SR is probably well known to veterinarians. Detailed morphological descriptions were not available, although additional defects as e.g. fissure of the genitals and polypodia were reported.

Pedigree analyses included seven generations in most cases, while nine generations pedigrees were available in some cases. In a number of cases, pedigrees were incomplete due to unregistered descent. One case was omitted from the calculations as the descent of dam of an affected calf was unknown. The 29 SR cases were progeny of 29 sires.

Twenty-one SR affected calves were genetically related (Figure 1). Of these, 18 SR cases had a common ancestor in the paternal and maternal pedigrees (inbreeding loops). All sires producing SR cases were purebred Holsteins. Overall 106 ancestors with multiple occurrences were identified by analysis of the individual SR pedigrees. Usually the number of repetitions ranged from two (48 ancestors) to seven (six ancestors). However, three sires (I/2, II/1 and III/2 in Figure 1) were repeated 61,58 and 22 times, respectively. In addition to the pedigree including 21 cases, a minor pedigree with a few cases of SR were identified (Figure 2). Three cases of SR were progeny of the same grandfather, and two of the grandmothers were related while the third was of unknown descent.

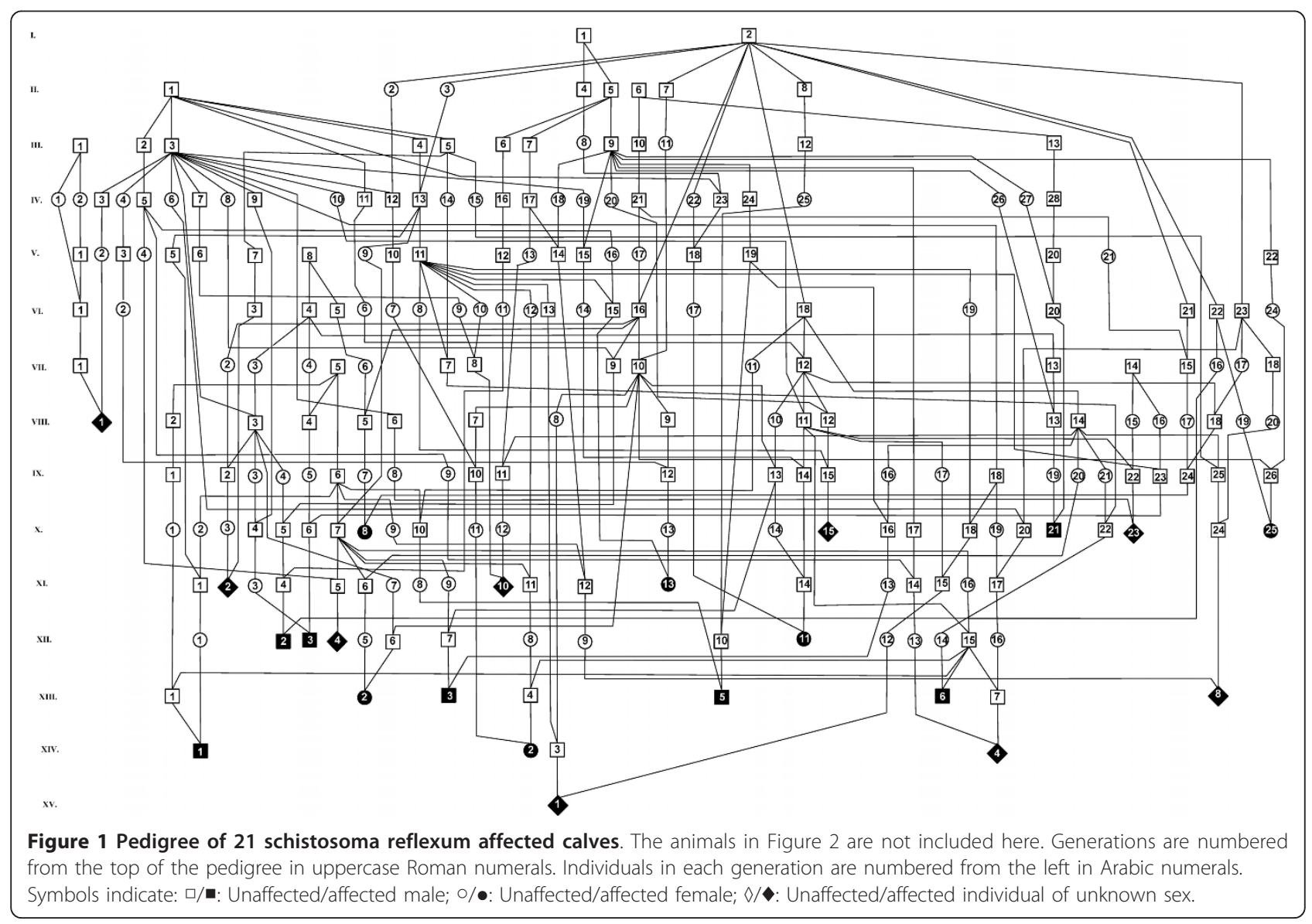




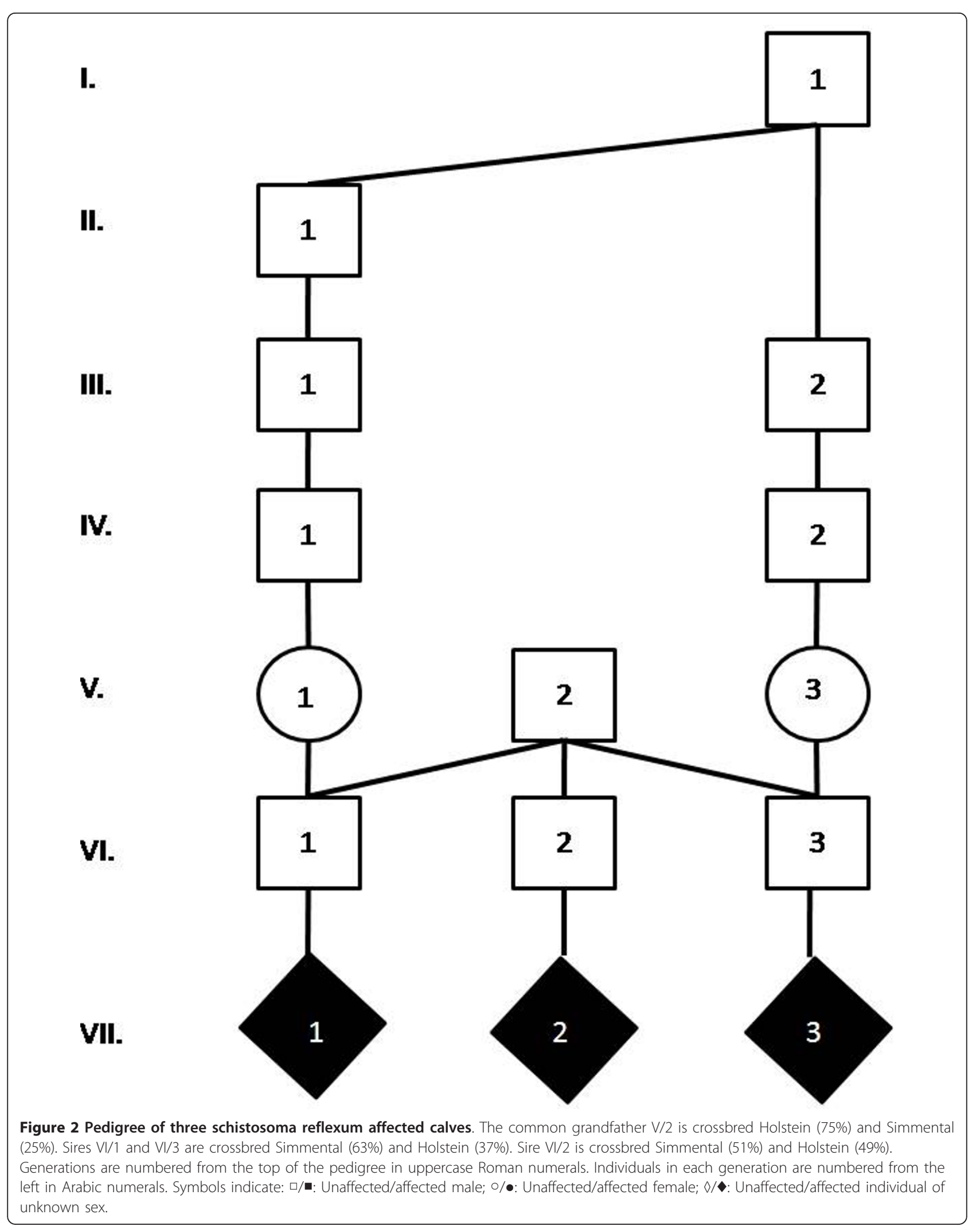


For comparison, 15 additional sires not fathering SR affected calves were analysed. These 15 sires were not of the same lines as the sires fathering SR calves. Of the three sires (I/2, II/1 and III/2) often present in the pedigrees of SR calves (Figure 1), solely I/2 occurred in these comparative pedigrees but only rarely. Other ancestors with repeated occurrence in SR pedigrees hardly appeared in the comparative pedigrees thus indicating that affected calves shared common ancestors different from those shared by the unaffected offspring.

The inbreeding coefficient was calculated for SR calves and the sires selected for comparison. The coefficient was calculated only for calves with common ancestors up to and including the $5^{\text {th }}$ generation in the parental pedigrees. For SR calves, only 11 individuals complied with this requirement. All 11 calves were included in the pedigree shown in Figure 1, and they had an average Fx of $0.94 \%$ (range: $0.20 \%$ to $2.34 \%$ ). The average inbreeding coefficient of the sires fathering SR calves was $1.55 \%$. The Fx of control Holstein sires not having registered SR affected offspring was $0.03 \%$, while the average coefficient of all sires in the Czech registry was $0.67 \%$. If only registered sires with a coefficient greater than zero were included, the average inbreeding coefficient was $2.49 \%$.

During the period 1986-2001, 2740 Holstein sires entered the Holstein pedigree herd book in the Czech Republic. Thus, $0.84 \%$ of Holstein sires fathered a SR calf.

\section{Discussion}

Analysis of pedigree data showed that 24 out of 29 registered SR cases occurred in two breeding lines (Figures 1 and 2). Within the large pedigree (Figure 1), some animals as e.g. sire XII/15, were genetically closely related to several SR cases. It should be clearly emphasized, that in a large complicated pedigree such as that in Figure 1, the common ancestors may occur by chance, especially if they have been widely used. This is the case for I/1 (Osborndale Ivanhoe, born 1952, US1189870), I/2 (Round Oak Rag Apple Elevation, born 1965, US1491007), II/1 (Pawnee Farm Arlinda Chief, born 1962, US1427381) and III/2 (S-W-D Valiant, born 1973, US1650414) that are important breeding sires used worldwide in Holstein cattle breeding. Sires as these will by chance occur the pedigree of defective Holstein calves [7]. However, the occurrence of sires such as XII/15 (Figure 1) and V/2 (Figure 2) related to several cases of SR may indicate a genetic aetiology.

In addition to the 29 SR cases included in this study, six other SR cases were registered (data not shown). Five of these were purebred Czech Simmentals or Simmentals crossbred with Ayrshire or a beef breed, while one case was of unknown descent. These findings show that SR is not restricted to the Holstein breed in the Czech Republic.

Although not all cases of SR occurred in a familial pattern, the findings of sires genetically associated with multiple cases indicate that the SR is inherited. Familial occurrence of SR cases has been reported previously [8]. Inbreeding loops might have been recognised in all cases if sufficient information on ancestors had been available. But due to the structure of cattle breeding, common ancestors and thus inbreeding loops would probably have been found by chance and therefore not provided any clear evidence for the inheritance. Studies of multiple closely related cases by molecular techniques such as SNP-based association mapping [9] would probably be most helpful in demonstrating a genetic aetiology. To ensure the accurate diagnosis that is needed to obtain a uniform collection of SR cases for molecular examination, further research should be carried out to establish the morphology of SR cases in detail. It can not be neglected that different mutations may be associated with a SR phenotype.

Based on the present results and those of others [3,5], cases of SR seems to occur in patterns consistent with autosomal recessive inheritance. X-linked recessive inheritance seems unlikely as affected males and females occur after breeding between unaffected animals and dominant inheritance is not likely as ancestors most likely were unaffected by this lethal syndrome [3]. Also, a non-genetic aetiology seems unlikely as cases occurred as isolated incidents and as cases of SR occur in twins with only one progeny being affected [10-14].

To confirm the genetic aetiology of SR and to establish a collection of cases for molecular investigations, a breeding trial is recommended where a sire that have had a SR affected offspring is mated to closely related females, e.g. some of his own daughters. Until then it is recommended to use such sires with caution to avoid unintended spread of deleterious genes in the population.

\section{Conclusions}

The findings are consistent with SR being inherited autosomal recessively. Further studies are however needed to confirm this and therefore a breeding trial is recommended where a suspected heterozygous sire is mated to closely related females.

\section{Acknowledgements}

The author thanks Kamila Senkyrova and Libor Vecerek for technical assistance, and John P. McAvoy for language revision. The research was supported by the Ministry of Education, Youth and Sports, MSM6007665806, and by the South Bohemia University (Project No. 022/2010/Z).

\section{Authors' contributions}

JC made the design of the study. He found the common ancestors, made the common pedigrees, evaluated the control pedigrees, inbreeding 
coefficients, wrote the manuscript, and formulated conclusions. The author read and approved the final manuscript.

\section{Competing interests}

The author declares that they have no competing interests.

Received: 6 October 2011 Accepted: 2 April 2012 Published: 2 April 2012

\section{References}

1. Saperstein G: Congenital abnormalities of internal organs and body cavities. Vet Clin North Amer 1993, 9(1):115-125.

2. Bezek DM, Frazer GS: Schistosomus reflexus in large animals. Comp Cont Educ Vet Pract 1994, 16:1393-1396.

3. Buck BC, Ulrich $R$, Wohlsein P, Distl O: A case of schistosoma reflexum in a black and white German Holstein calf. Dtsch Tierarztl Wchschr 2009, 10:363-368.

4. Cavalieri J, Farin PW: Birth of a Holstein freemartin calf co-twinned to a schistosomus reflexus fetus. Theriogenol 1999, 52:815-826.

5. Laughton KW, Fisher KRS, Halina WG, Partlow GD: Schistosomus reflexus syndrome: a heritable defect in ruminants. Anat Histol Embryol 2005, 34:312-318.

6. Plemdat. [http://iserv.plemdat.cz/].

7. Agerholm J, Bendixen C, Andersen O, Arnbjerg J: Complex vertebral malformation in Holstein calves. J Vet Diagn Invest 2001, 13:283-289.

8. Jackson PG: Schistosomus reflexus. Vet Rec 1987, 121:235-236.

9. Charlier C, Coppieters W, Rollin F, Desmecht D, Agerholm J, Cambisano N, Carta E, Dardano S, Dive M, Fasquelle C, Frennet J-C, Hanset R, Hubin X, Jorgensen C, Karim L, Kent M, Harvey K, Pearce BR, Simon P, Tama N, Nie H, Vandeputte S, Lien S, Longeri M, Fredholm M, Harvey RJ, Georges M: Highly effective SNP-based association mapping and management of recessive defects in livestock. Nat Genet 2008, 40:449-454.

10. Bedford PGC: Schistosoma reflexus in a goat: a case report. Vet Rec 1967, 80:326.

11. Knight RP: The occurrence of schistosomus reflexus in bovine dystocia. Aust Vet J 1996, 73:105-107.

12. Morton DH, Cox JE: Bovine dystocia: a survey of 200 cases met with in general practice. Vet Rec 1968, 82:530-537.

13. Smith ID: Schistosomus reflexus in conjoined twin lambs. Vet Rec 1969, 85:138-139.

14. Wiliams El: Schistosomus reflexus as twin to normal calf. Vet Rec 1952, 64:422.

\section{Submit your next manuscript to BioMed Central and take full advantage of:}

- Convenient online submission

- Thorough peer review

- No space constraints or color figure charges

- Immediate publication on acceptance

- Inclusion in PubMed, CAS, Scopus and Google Scholar

- Research which is freely available for redistribution

Submit your manuscript at www.biomedcentral.com/submit
Biomed Central 